\title{
Article \\ Effect of the Particle Size on the TDA Shear Strength and Stiffness Parameters in Large-Scale Direct Shear Tests
}

\author{
Hany El Naggar *, Khaled Zahran and Ahmed Moussa
}

check for

updates

Citation: El Naggar, H.; Zahran, K.; Moussa, A. Effect of the Particle Size on the TDA Shear Strength and Stiffness Parameters in Large-Scale Direct Shear Tests. Geotechnics 2021, 1, 1-17. https://doi.org/10.3390/ geotechnics1010001

Received: 13 November 2020

Accepted: 15 January 2021

Published: 25 January 2021

Publisher's Note: MDPI stays neutral with regard to jurisdictional claims in published maps and institutional affiliations.

Copyright: (c) 2021 by the authors. Licensee MDPI, Basel, Switzerland. This article is an open access article distributed under the terms and conditions of the Creative Commons Attribution (CC BY) license (https:// creativecommons.org/licenses/by/ $4.0 /)$.
Department of Civil \& Resource Engineering, Dalhousie University, Halifax, NS B3H 4R2, Canada; kh213504@dal.ca (K.Z.); ahmed.moussa@dal.ca (A.M.)

* Correspondence: hany.elnaggar@dal.ca

\begin{abstract}
The increase in the number of discarded tires every year is becoming a major issue all over the world. Tires stockpiles and landfills have become a critical issue as they are considered a fertile environment for the breeding of rats and insects, a real fire hazard that may take up to months to extinguish and occupy a valuable, large area of land. One of the safest effective ways of recycling tires is that to use them as backfilling material, among different usages, in civil engineering projects due to their low unit weight and specific gravity. However, to use any material in the construction industry, several material properties must be evaluated, including the shear strength and stiffness parameters. Many factors control the measured parameters. One main factor that is known to have a significant effect is the particle size. This paper focuses on evaluating the effect of the particle size on the shear strength and stiffness parameters of six tire-derived aggregate (TDA) samples having particle sizes range between $(9.5-101.6 \mathrm{~mm}$ ) using a large-scale direct shear machine. The tests were conducted under three normal stresses: $50.1,98.8$ and $196.4 \mathrm{kPa}$ using a constant shearing rate of $0.5 \mathrm{~mm} / \mathrm{min}$. The results of this study showed an increasing angle of internal friction as the maximum particle size increases. Moreover, the secant shear modulus also exhibited an increase by increasing the maximum particle size. Furthermore, equations to estimate the stress-strain curves of Type A-TDA for different confidence levels were developed, and their predictions were compared with experimental results to assess their suitability.
\end{abstract}

Keywords: large scale direct shear test; tire derived aggregates; aggregate size effect

\section{Introduction}

The number of scrap tires generated every year all over the world is rapidly increasing. The reason behind this increase is that the number of vehicles is growing at an unprecedented rate, and the current technology is not targeting new means for recycling tires. However, it is engaged in the development of renewable fuels. In 2015, Americans disposed of around 250 million tires. In the same year, approximately 35 million scrap tires were discarded in Canada.

This increasing number of scrap tires is becoming a significant hazard for the environment as the primary means of getting rid of scrap tires is either by stockpiling or disposing of them in landfills. These solutions possess serious hazards and are not environmentally acceptable as they are considered a fertile environment for insects and mosquitoes to breed and are prone to fire hazards as tires can catch fire easily, and it was noted that it is challenging to extinguish them [1].

Fortunately, some methods for recycling scrap tires, including using them as ground rubbers for different applications as in children's playgrounds and gyms, have started to gain popularity. Last but not least, they could be used in several civil engineering projects as tire-derived aggregates (TDA) in which scrap tires are shredded into smaller pieces and used mainly as light backfill material, among other usages. Some of these usages include use of TDA products as an additive to alleviate the inferior geotechnical properties of subgrade deposits of clay soil with high expansivity, [2,3]. Moreover, Shahrokhi-Shahraki 
et al. [4] investigated the use of pulverized waste tires, either on their own or mixed with soil (well graded sand), to act as adsorptive fill materials, demonstrating adsorption of organic/inorganic contaminants (benzene, toluene, ethylbenzene, and xylene (BTEX) components and two heavy metal ions $\left(\mathrm{Pb}^{2+}\right.$ and $\left.\mathrm{Cu}^{2+}\right)$. ASTM D6270 [5] classifies TDA into two types; A and B. Type A is roughly $75-100 \mathrm{~mm}$ in size with a maximum particle dimension measured in any direction of $200 \mathrm{~mm}$. On the other hand, Type B is about 150-305 $\mathrm{mm}$ in size, with a maximum particle dimension in any direction of $450 \mathrm{~mm}$ [6].

Type A is typically used as an insulation material for road projects or a fill material behind retaining walls, whereas type B is mostly used as an embankment fill. Shredded tire products have a number of desirable geotechnical properties that can improve the performance of civil engineering infrastructure. Such products weigh only one-third to half as much as conventional granular backfill materials. The specific gravity of TDA ranges from 1.15 to 1.21 , while the specific gravity of conventional backfill ranges from 2.55 to 2.75 [7]. Over the previous two centuries, TDA has been utilized as a drainage material beneath perforated leachate collection pipes as the permeability of TDA is 10 times higher than that of gravel. In addition, TDA is regarded as a good thermal insulator and is eight times more effective than regular soil in this respect [8]. The use of TDA as lightweight backfill material in embankments and retaining wall projects has been examined by many researchers [1,9]. TDA has also been used under shallow foundations and in trench fill projects above and around buried pipes and culverts to improve the arching mechanism [10-13]. In addition, owing to the excellent damping characteristics of TDA, it is also used as a vibration dampening, [14]. For example, Moussa and El Naggar [15] found that TDA-infilled buried trenches could improve the screening effectiveness of the buried infilled trenches compared to other materials.

One of the main characterizations, which is essential for TDA adoption in civil engineering projects, is their geotechnical characterization. However, TDA particles are considered large in size compared to the available standard testing equipment, and practitioners are forced to test smaller TDA particle sizes not representative of the real sizes used in construction projects. Hence, the main focus of this paper is to study the particle size effect on the shear strength parameters of TDA using a large-scale direct shear machine. Several studies were done on granular and fine soils to study the effect of the particle size on the shear strength parameters, while none considered the particle size effect of TDA.

For the granular materials, one of the earliest studies for the particle size effect for coarse-grained soils was done by Kim and Ha [16]. The authors in this research investigated the shear strength parameters of coarse-grained soils for three samples with three different maximum particle sizes; $4.75 \mathrm{~mm}, 7.9 \mathrm{~mm}$ and $15.9 \mathrm{~mm}$. The samples were tested in a pure state, supported with a soft geogrid, and supported with a stiff geogrid. The testing was undertaken using a shear box with dimensions of $300 \mathrm{~mm} \times 300 \mathrm{~mm}$ with a shear rate of $1 \mathrm{~mm} / \mathrm{min}$. The tests were performed under three normal stresses: $98 \mathrm{kPa}, 196 \mathrm{kPa}$ and $294 \mathrm{kPa}$. The results showed that the angle of internal friction increased from $40.56^{\circ}$ for the $4.75 \mathrm{~mm}$ sample, up to $54.04^{\circ}$ for the $15.9 \mathrm{~mm}$ sample.

Moreover, Islam et al. [17] studied the effect of particle size on the shear strength parameters of sands. A series of direct shear tests were conducted on 10 samples in total. Eight samples with uniform particle sizes $(0.075,0.15,0.212,0.3,0.6,1.18,1.72$ and $2.76 \mathrm{~mm})$ and two samples with graded particle sizes $(0.075-1.18 \mathrm{~mm}$ and $0.075-2.36 \mathrm{~mm})$. Tests were performed with a shear box with a diameter of $50.8 \mathrm{~mm}$ under a constant rate. The specimens had unit weight range of 12.65 to $15.7 \mathrm{kN} / \mathrm{m}^{3}$ and void ratio range of 0.38 to 0.95 . The results showed that the angle of internal friction increased from $35.54^{\circ}$ up to $42.24^{\circ}$ for the samples with uniform particle sizes. For the two samples with graded particle sizes, the internal friction angle increased from $41.18^{\circ}$ to $41.83^{\circ}$.

Furthermore, Vangla and Latha [18] conducted a series of direct shear tests to investigate the influence of the particle size on the shear strength of sands. The tests were conducted on three samples; fine, medium and coarse. The coarse sample had a maximum particle size of $4.75 \mathrm{~mm}$. The medium sample had a maximum particle size of $2 \mathrm{~mm}$, while 
the fine sample had a maximum particle size of $0.425 \mathrm{~mm}$. All samples had the same relative density, void ratio and unit weight. The specimens' relative density, void ratio and unit weight were $70 \%, 0.68$ and $15.2 \mathrm{kN} / \mathrm{m}^{3}$, respectively. The tests were conducted using a large-scale direct shear test with a shear box of dimensions $300 \mathrm{~mm} \times 300 \mathrm{~mm}$. The shearing rate was $1 \mathrm{~mm} / \mathrm{min}$ under three normal stresses: $21 \mathrm{kPa}, 37 \mathrm{kPa}, 58 \mathrm{kPa}$. The results showed that the ultimate friction angle increased from $35.9^{\circ}$ for the fine sand up to $38.9^{\circ}$ for the coarse sand.

As shown above, detailed studies were conducted to study the particle size effect on the shear strength parameters of coarse and fine-grained soils. It is noted that the shear resistance of the sample increases as the particle size increases. However, according to the author's knowledge, no studies were performed on TDA to study the particle size effect on the TDA's shear strength or stiffness. Furthermore, a non-linear regression analysis was carried out to develop stress-strain curves of TDA type A considering the various TDA maximum aggregates size. Lastly, the developed equations of stress-strain curves of TDA type A were compared with other curves obtained from the literature.

\section{Experimental Setup and Material}

\subsection{Experimental Setup}

Figure 1 shows the large-scale direct shear test setup with a sample size of $305 \mathrm{~mm}$ by $305 \mathrm{~mm}$ and a height of $230 \mathrm{~mm}$ that was used in this study. The height of the lower movable part of the shear box was $90 \mathrm{~mm}$, and the height of the upper part was $140 \mathrm{~mm}$.

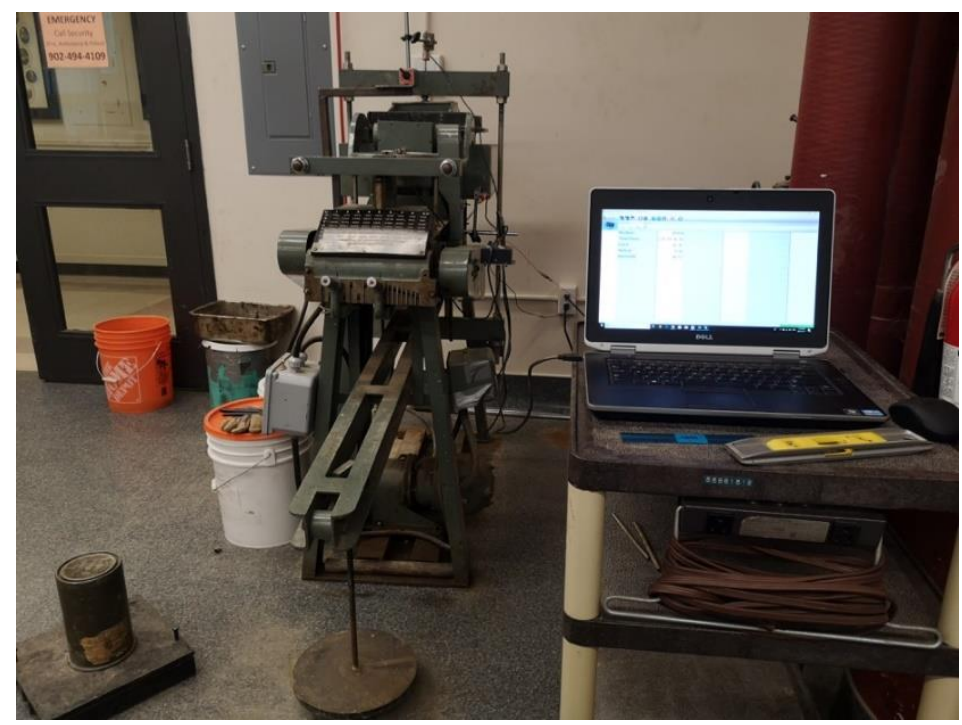

Figure 1. Large-scale direct shear apparatus.

This setup can shear a sample up to $50 \mathrm{~mm}$ horizontal displacement with a shearing rate ranging between $0.02-2 \mathrm{~mm} / \mathrm{min}$. The setup has a load cell and two linear variable displacement transducers (LVDTs), which were used to measure the shear force $(\mathrm{kN})$, horizontal displacement $(\mathrm{mm})$ and vertical displacement $(\mathrm{mm})$. The load cell and the 2 LVDTs were connected to a data acquisition system to record the data from the test. The direct shear apparatus can apply normal stresses ranging between 50.1-293.2 kPa using a deadweight loading mechanism.

\subsection{Material}

The TDA used in this research was shredded at Halifax C\&D Recycling Ltd. (Goodwood, NS, Canada), shown in Figure 2, using the conventional method of tires shredding by passing the tires through shredders under ambient temperature until reaching the desired particle size range. In this research, five samples having different maximum particle sizes $\left(\mathrm{D}_{\max }\right)$; of $19.05,38.1,50.8,76.2$, and $101.6 \mathrm{~mm}$ were considered. 


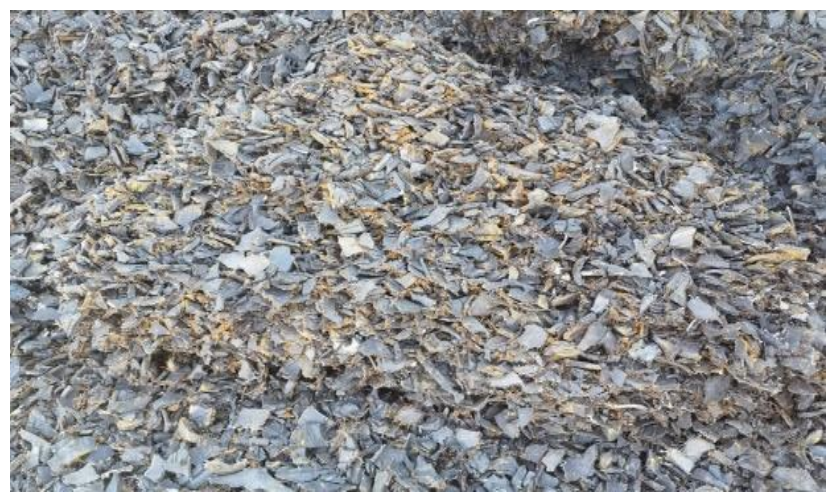

Figure 2. Tire-derived aggregate (TDA) from Halifax C\&D recycling Ltd.

Any protruding steel in the samples was removed entirely. So, the shear resistance resulting from these samples should be more conservative than the actual TDA used in civil engineering projects commonly used with their protruding steel. The samples were sieved following the procedures of ASTM C136/C136M-14. All the samples had a particle size range starting from $9.5 \mathrm{~mm}$ and up to the maximum particle size $\left(D_{\max }\right)$ existing in the sample. Due to the particle size distribution for the five samples being tested, the samples fall under the Type A-TDA classification.

The characteristics of the five samples are given below in Table 1. The samples had an increasing maximum particle size $\left(D_{\max }\right)$, which qualifies the samples for the study of the effect of the particle size effect on the shear strength parameters of TDA. The gradation curves of the five samples are shown in Figure 3.

Table 1. Characteristics of the TDA used in the research.

\begin{tabular}{cccccc}
\hline Characteristics & Sample \#1 & Sample \#2 & Sample \#3 & Sample \#4 & Sample \#5 \\
\hline $\mathbf{D}_{\mathbf{1 0}}(\mathbf{m m})$ & 9.7 & 12 & 12.8 & 13 & 15 \\
$\mathbf{D}_{\mathbf{3 0}}(\mathbf{m m})$ & 12.4 & 16.5 & 19 & 25 & 27.5 \\
$\mathbf{D}_{\mathbf{5 0}}(\mathbf{m m})$ & 14 & 25 & 29.5 & 33 & 39 \\
$\mathbf{D}_{\mathbf{6 0}}(\mathbf{m m})$ & 15.5 & 27.5 & 33 & 39 & 45 \\
$\mathbf{D}_{\mathbf{m a x}}(\mathbf{m m})$ & 19.05 & 38.1 & 50.8 & 76.2 & 101.6 \\
Size Range $(\mathbf{m m})$ & $9.5-\underline{\mathbf{1 9 . 0 5}}$ & $9.5-\underline{\mathbf{3 8 . 1}}$ & $9.5-\underline{\mathbf{5 0 . 8}}$ & $9.5-\underline{\mathbf{7 6 . 2}}$ & $9.5-\underline{\mathbf{1 0 1 . 6}}$ \\
$\mathbf{C}_{\mathbf{u}}$ & 1.63 & 2.3 & 2.58 & 3 & 3 \\
$\mathbf{C}_{\mathbf{c}}$ & 1.04 & 0.83 & 0.85 & 1.23 & 1.12 \\
Specific Gravity $\left(\mathbf{G}_{\mathbf{s}}\right)$ & 1.03 & 1.05 & 1.06 & 1.06 & 1.09 \\
\hline
\end{tabular}

The coefficient of uniformity $\left(C_{u}\right)$ was calculated as follows:

$$
C_{u}=D_{60} / D_{10}
$$

while the coefficient of curvature $\left(C_{c}\right)$ was calculated as follows:

$$
C_{c}=D_{30}^{2} /\left(D_{60} \times D_{10}\right)
$$




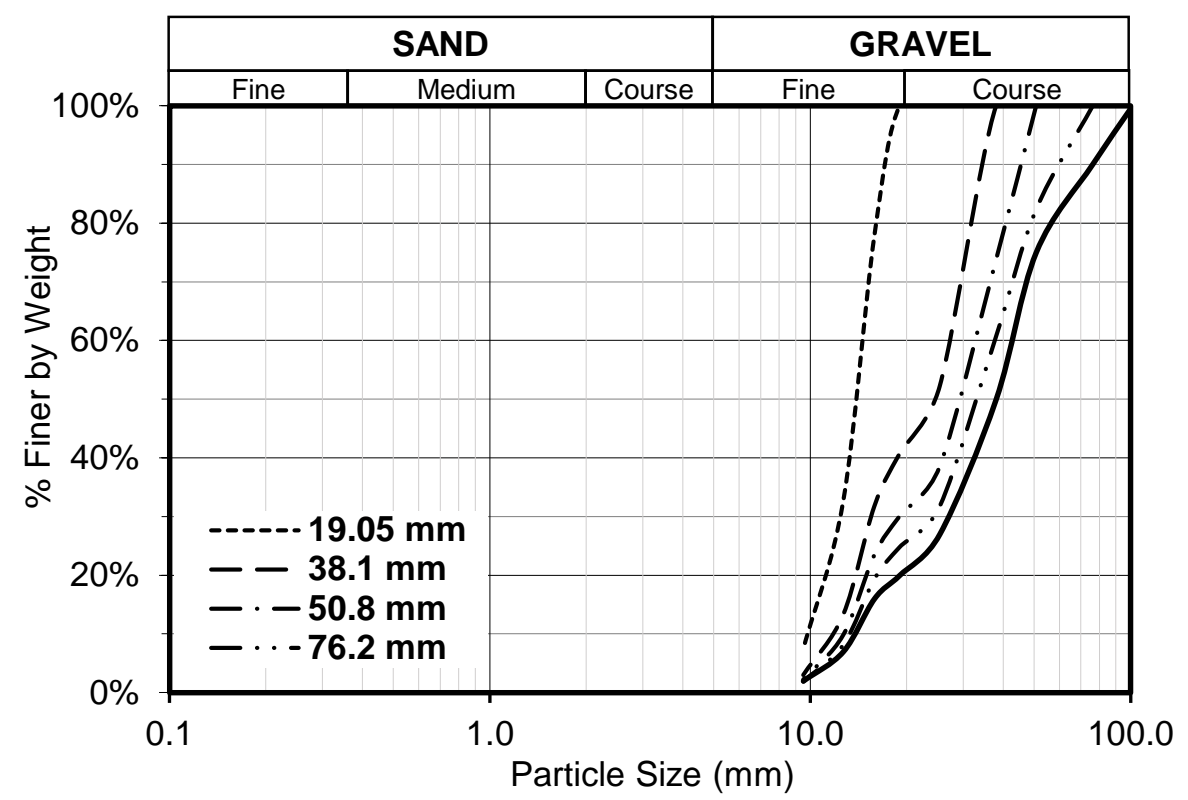

Figure 3. Particle size distribution of the tested samples.

\subsection{Sample Preparation and Testing Scheme}

\subsubsection{Sample Preparation}

Firstly, the samples were sieved following ASTM C136/C136M [19]. Then, the protruding steel was removed entirely. After that, the retained particles on each sieve were mixed properly altogether to have fewer voids and make sure that the failure plan inside the shear box is made of a representative portion of the sample.

Furthermore, proper compaction was applied to the samples with total compaction energy of 38,000 (Joules) within the range suggested by ASTM D6270-08 [2] which stated that if compaction energy is higher than $60 \%$ of standard Proctor energy it will not affect the compacted unit weight of TDA significantly. Compaction was done using a modified Proctor hammer following the procedures of ASTM D1557 [20]. To achieve the required compacted unit weight, TDA specimens were placed in five layers inside the shear box. Each layer was subjected to 75 blows till reaching the desired compacted unit weight, with a total of 375 blows for each sample.

\subsubsection{Testing Scheme}

A series of large-scale direct shear tests were performed in accordance with ASTM D3080/D3080M [16] under strain-controlled conditions. The shear stress, horizontal displacement and vertical displacement were recorded up to $14 \%$ horizontal strain, and the angle of internal friction and cohesion were calculated at $10 \%$ relative lateral displacement as recommended by ASTM D3080 [21]. The samples were subjected to three normal stresses; $50.1 \mathrm{kPa}, 98.8 \mathrm{kPa}$ and $196.4 \mathrm{kPa}$. Normal stresses were selected based on real soil conditions, and they were applied using a deadweight loading mechanism. The TDA specimen unit weight was observed to increase immediately after the application of normal stress, followed by a small amount of creep settlement (less than $2 \mathrm{~mm}$ ). An average period of 15 to 20 minutes was considered after the load application to ensure that there is no further vertical displacement before starting the shearing.

The TDA specimens were sheared at a constant shearing rate of $0.5 \mathrm{~mm} / \mathrm{min}$. A low shearing rate was chosen to avoid overestimating the calculated shear resistance. The chosen shearing rate was less than that used in the literature to the best of the authors' knowledge $[9,16,18,22-24]$.

The specimens' dry density $\left(\gamma_{d}\right)$ and void ratio $(e)$ before shearing and after applying the normal stresses was calculated to assure that the tests were undertaken under similar conditions, and it is summarized below in Table 2. It could be noted from Table 2 that the 
void ratios of all samples at a given normal stress were relatively similar. Since the TDA used herein was from the same supplier; as a result, the data regarding the specific gravity and void ratios were the same. This finding was also indicated by Yi et al. [25], where the authors obtained the minimum and maximum dry unit weights and void ratios, specific gravity and initial void ratios of two types of TDA. Different samples from the same TDA type (i.e., tires obtained from the same source) showed that the specific gravity, void ratio and maximum and minimum dry densities and void ratios were similar. This was because the amount of steel in the same type of TDA was similar.

Table 2. Dry density and void ratio before shearing.

\begin{tabular}{cccccccc}
\hline & \multicolumn{6}{c}{ Density $\left(\mathbf{k N} / \mathbf{m}^{\mathbf{3}}\right)$ and Void Ratio before Shearing } \\
\cline { 2 - 7 } Maximum Particle Size $\left(\boldsymbol{D}_{\mathbf{m a x}}\right)$ & \multicolumn{2}{c}{$\mathbf{5 0 . 1} \mathbf{~ k P a}$} & \multicolumn{2}{c}{$\mathbf{9 8 . 8} \mathbf{~ k P a}$} & \multicolumn{2}{c}{$\mathbf{1 9 6 . 4} \mathbf{~ k P a}$} \\
\cline { 2 - 7 } & $\gamma_{\boldsymbol{d}}$ & $\boldsymbol{e}$ & $\gamma_{\boldsymbol{d}}$ & $\boldsymbol{e}$ & $\gamma_{\boldsymbol{d}}$ & $\boldsymbol{e}$ \\
\hline $19.05 \mathrm{~mm}$ & 6.3 & 0.60 & 6.6 & 0.53 & 7.3 & 0.38 \\
$38.1 \mathrm{~mm}$ & 6.3 & 0.64 & 6.7 & 0.54 & 7.3 & 0.41 \\
$50.8 \mathrm{~mm}$ & 6.4 & 0.62 & 6.8 & 0.53 & 7.3 & 0.42 \\
$76.2 \mathrm{~mm}$ & 6.3 & 0.65 & 6.7 & 0.55 & 7.4 & 0.41 \\
$101.6 \mathrm{~mm}$ & 6.4 & 0.67 & 6.7 & 0.60 & 7.5 & 0.43 \\
\hline
\end{tabular}

\section{Results}

\subsection{Shear Strength}

Figures 4-6 show the shear stress-strain curves for the five TDA tested samples under the three normal stresses. The $19.05 \mathrm{~mm}$ sample showed the least shear stress-strain curve, while the $101.6 \mathrm{~mm}$ sample showed the highest shear stress-strain curves under the three normal stresses. Generally, the curves showed a bi-linear behavior with a very steep initial increase in shear stress. Then, the shear stress continued to increase with a lower slope up to $10 \%$ horizontal strain, after which most of the curves tended towards peak strength.

Furthermore, the TDA samples exhibited contractive behaviour under all the applied normal stresses as shown in Figures 4-6. Generally, a higher contraction occurs when the normal stress applied to the sample increases. In addition, the smallest sample $19.05 \mathrm{~mm}$ exhibited the highest volumetric strain, however, the larger sample sizes had a lower and similar volumetric strain as the horizontal shear strain increases.

The angle of internal friction and cohesion were defined using the Mohr-Coulomb failure criterion. Due to the absence of the peak, the failure was considered to be at $10 \%$ horizontal strain as recommended by ASTM D3080 [21]. Figure 7 shows Mohr-Coulomb failure envelopes for the six samples. It can be noted that as the aggregate size increases, the shear Mohr-Coulomb failure envelopes turn counter clockwise, hence possessing higher shear strength.

From the failure envelopes shown in Figure 7, the angle of internal friction and cohesion were calculated using the Mohr-Coulomb failure equation, as shown below in Equation (3).

$$
\tau_{10 \%}=c+\sigma \tan \varphi
$$

where $\left(\tau_{10 \%}\right)$ is the shear stress at $10 \%$ horizontal strain, $(c)$ is the cohesion, which is the $y$-intercept, and $(\varphi)$ is the angle of internal friction. 


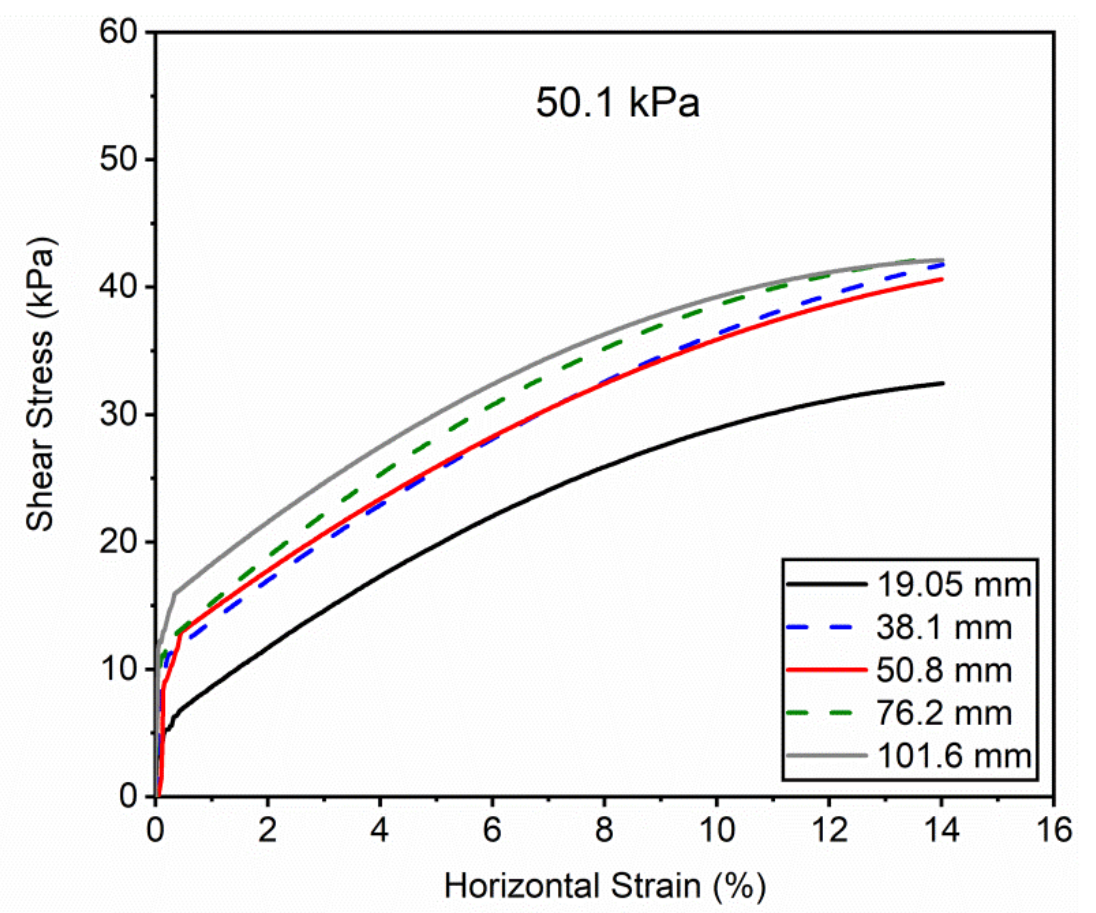

(a)

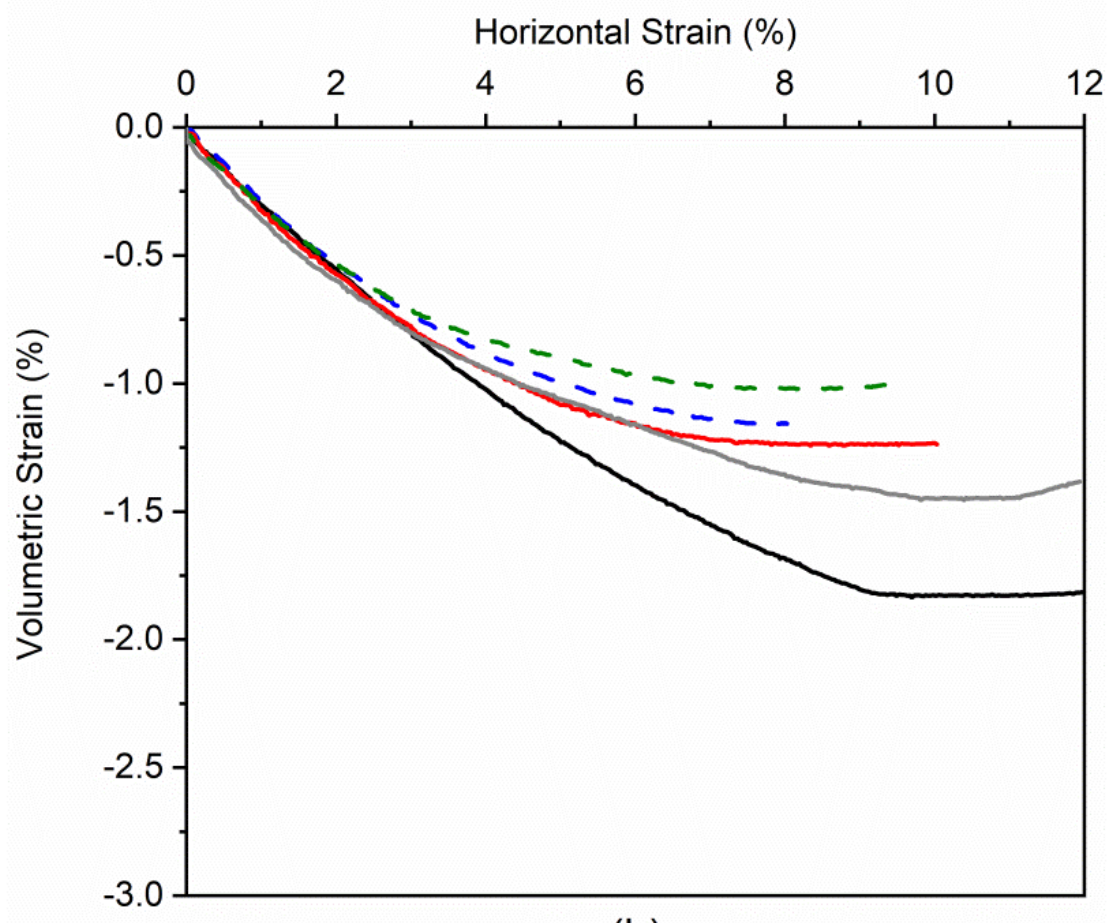

(b)

Figure 4. Internal shear behavior of TDA specimens under normal stress of $50.1 \mathrm{kPa}$ : (a) shear stress vs. horizontal strain; (b) volumetric strain vs. shear strain. 


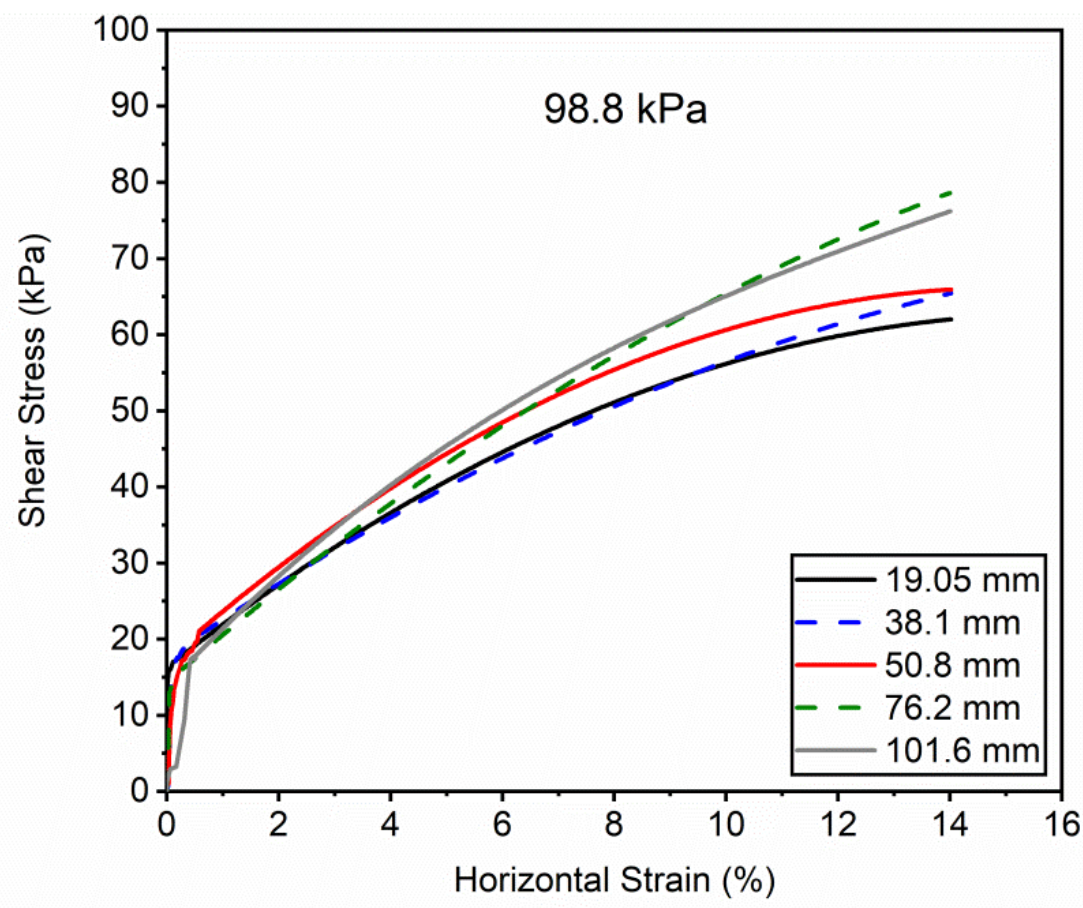

(a)

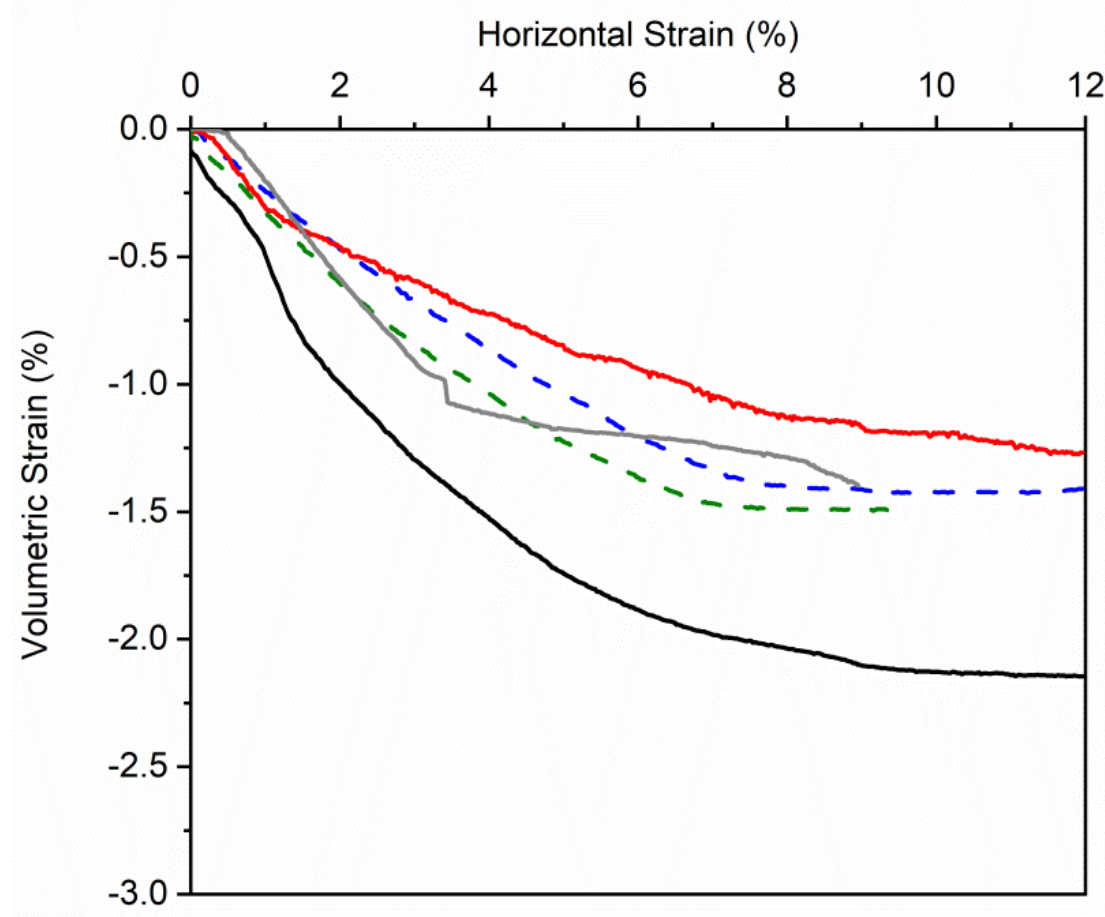

(b)

Figure 5. Internal shear behavior of TDA specimens under normal stress of $98.8 \mathrm{kPa}$ : (a) shear stress vs. horizontal strain; (b) volumetric strain vs. shear strain. 


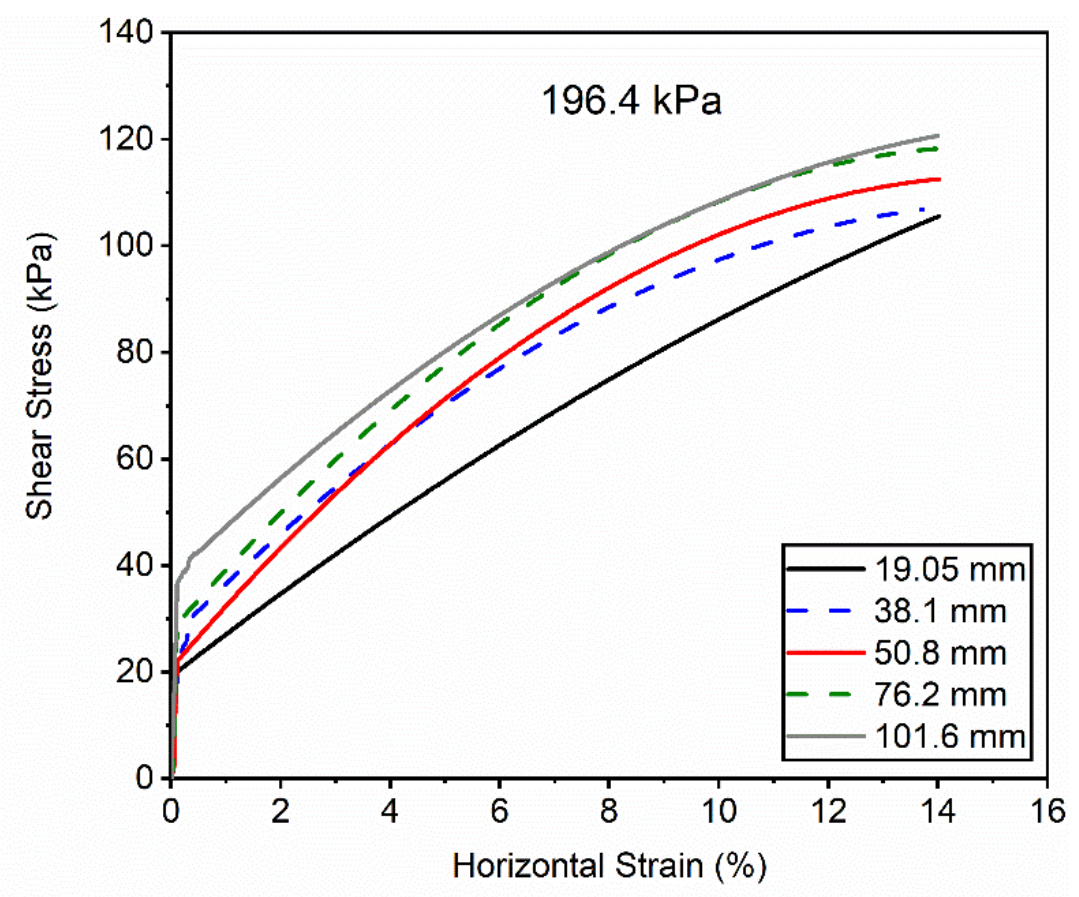

(a)

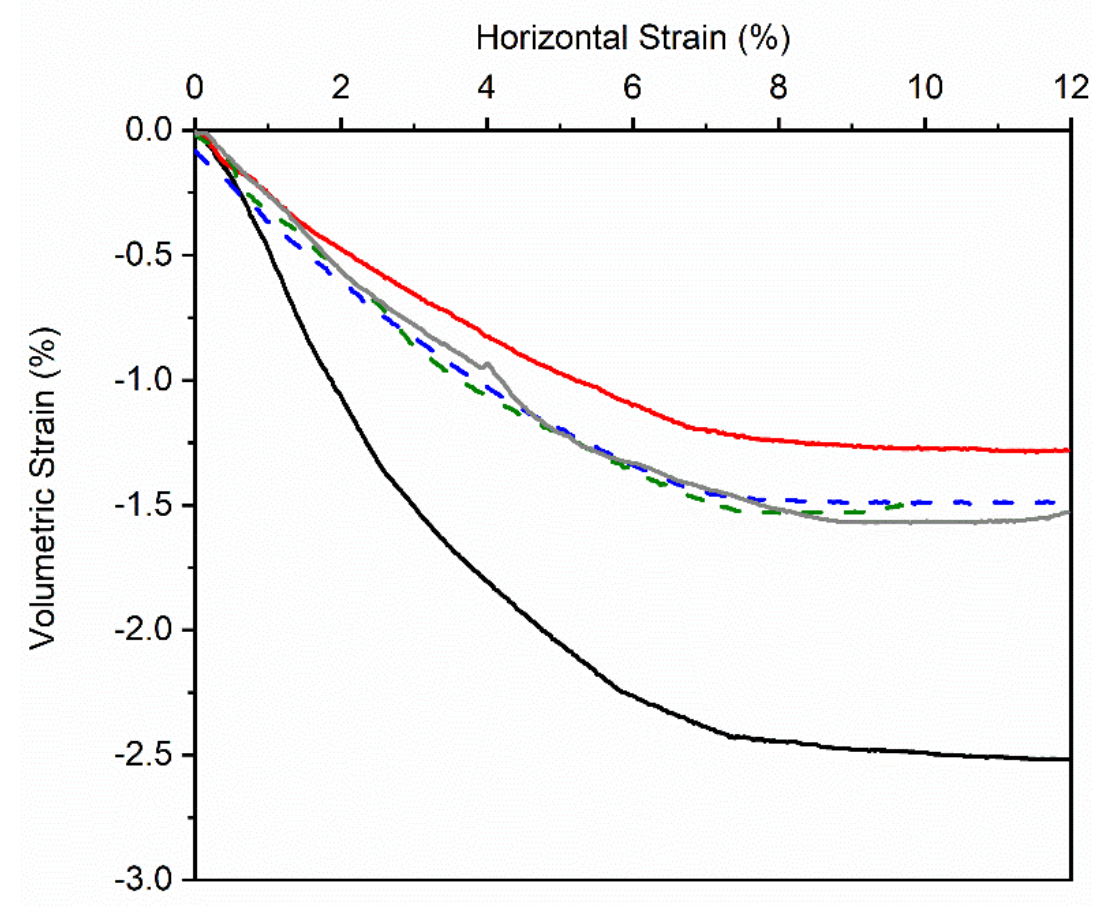

(b)

Figure 6. Internal shear behavior of TDA specimens under normal stress of $196.4 \mathrm{kPa}$ : (a) shear stress vs. horizontal strain; (b) volumetric strain vs. shear strain. 


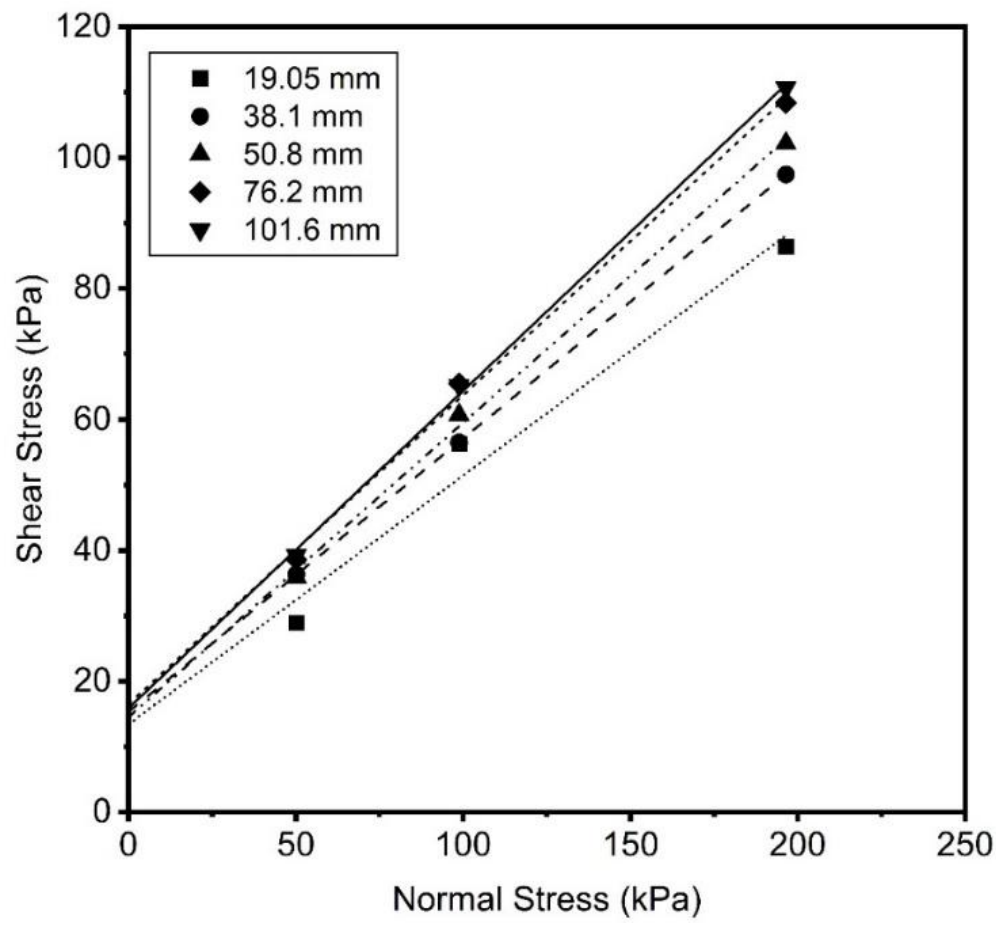

Figure 7. Mohr-Coulomb failure envelope.

The angle of internal friction and cohesion are illustrated in Figure 8 to ease their understanding. The angle of internal friction showed an increase by increasing the maximum particle size, while the cohesion did not show a particular trend, neither increasing nor decreasing. However, the maximum cohesion difference is $3.1 \mathrm{kPa}$, which will not affect the geotechnical design, and the angle of internal friction will govern the shear resistance. The apparent cohesion of TDA was due to the interlocking of the shredded tire aggregates. Also, it can be seen from the graph that the rate of increase in the friction angle almost stabilized after the $76.2 \mathrm{~mm}$ particle size.

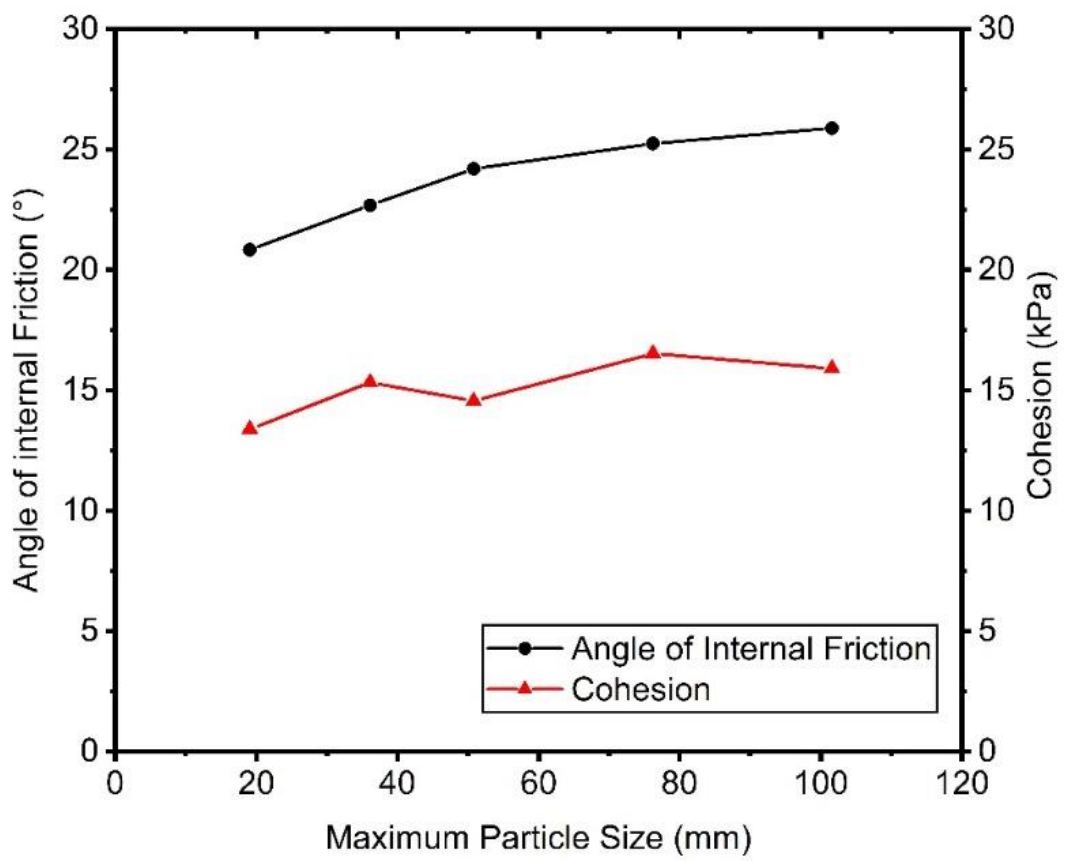

Figure 8. Mohr-Coulomb failure envelope. 


\subsection{Development of Stress-Strain Curves of TDA}

As shown in Figures 4-6, the highest stress-strain curves are corresponding to the larger TDA aggregate sizes, i.e., 76.2 and $101.6 \mathrm{~mm}$ samples. At the same time, the lowest stress-strain curve is corresponding to the $19.05 \mathrm{~mm}$ sample. This could indicate the aggregate size effect of TDA on the obtained stress-strain curves. Nevertheless, since the curves for the remaining samples (i.e., 38.1 and $50.8 \mathrm{~mm}$ samples) are overlapping with each other, it is not possible to develop stress-strain equations that are a function of the TDA aggregates size. Since there is a significant influence of the normal stresses on the stress-strain curves obtained, the developed equations herein will be only function in the normal stresses.

A non-linear regression analysis was conducted using Equation (4) to find the best fit for the experimental data of all samples at each normal stress. Furthermore, the adopted equation is an extension of the Classical Freundlich Model [25].

$$
\tau=a+b\left(\varepsilon_{h}\right)^{c}
$$

where $(\tau)$ is the shear stress in $\mathrm{kPa},(a, b$ and $c)$ are the fitting parameters and $\left(\varepsilon_{h}\right)$ is the horizontal strain. Moreover, to consider the effect of TDA aggregate size on the stressstrain curves, the $95 \%$ confidence level (CL) of the fitting parameters was calculated. The importance of calculating the upper confidence level (UCL) and lower confidence level (LCL) is to give an indication of the expected range of the strength parameters for different TDA aggregate sizes. As mentioned earlier, the developed curves are only function in the normal stress. The fitting parameters were expressed as 2 nd order polynomial equations, which are function in the normal stress magnitude. Figure 9 shows the non-linear curve fitting using Equation (5) for all samples at a normal stress of 50.1, 98.8 and $196.4 \mathrm{kPa}$. Furthermore, it could be noted from Figure 9 that the UCL and LCL boundaries correspond well to the largest and lowest stress-strain curves. Based on the values obtained for the fitting parameters, i.e., a, b and c, at each normal stress level, 2nd degree polynomial relationships between the fitting parameters and the normal stresses were obtained as listed in Table 3. The 2nd degree polynomial equation is as follows:

$$
a, b \text { or } c=p_{1}\left(\sigma_{v}^{\prime}\right)^{2}+p_{2} \sigma_{v}^{\prime}+p_{3}
$$

where $\left(\sigma_{v}^{\prime}\right)$ is the effective normal stress in $\mathrm{kPa}$ and $\left(p_{1}, p_{2}\right.$ and $\left.p_{3}\right)$ are the fitting parameters which are given in Table 3.

The equations developed to predict the range of stress-strain curves of Type A TDA for a different aggregate size were evaluated through the comparison with various experimental curves presented in the literature. Iranikhah and El Naggar [26] conducted a series of large-scale direct shear tests on TDA-gravel mixtures. The percentage of TDA by weight varied from $0 \%$ to $100 \%$ and the applied normal stresses were 50.1, 98.8 and $196.4 \mathrm{kPa}$. Figure 10 shows the histogram for the TDA material used by Iranikhah and El Naggar [26]. As shown in Figure 11, at all normal stresses, the stress-strain curves obtained by Iranikhah and El Naggar [26] are within the upper and lower bounds obtained in this work. Furthermore, it could be noted from Figure 8 that the maximum particle size used was $75 \mathrm{~mm}$; therefore, the curves obtained by Iranikhah and El Naggar [26] tend to be near the upper bound due to the relatively large particle size. 


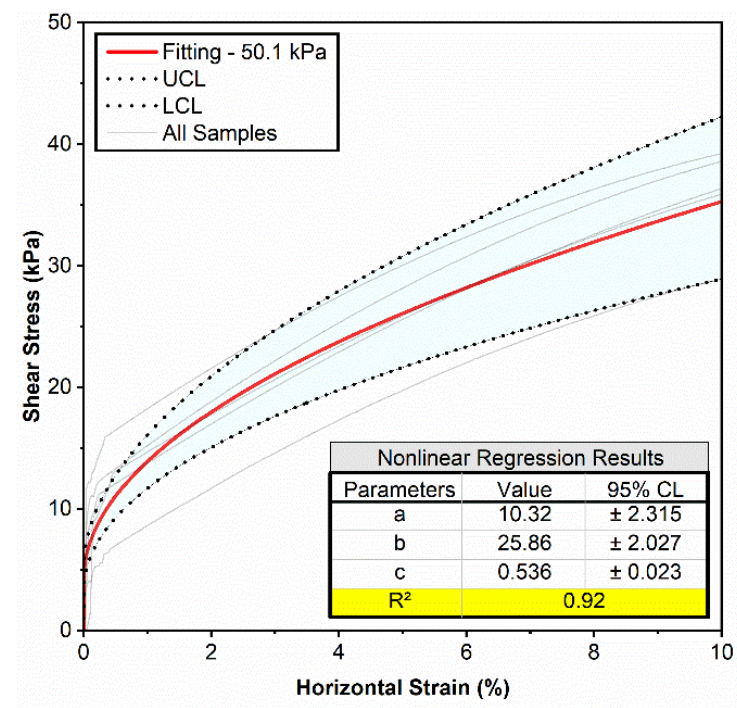

(a)

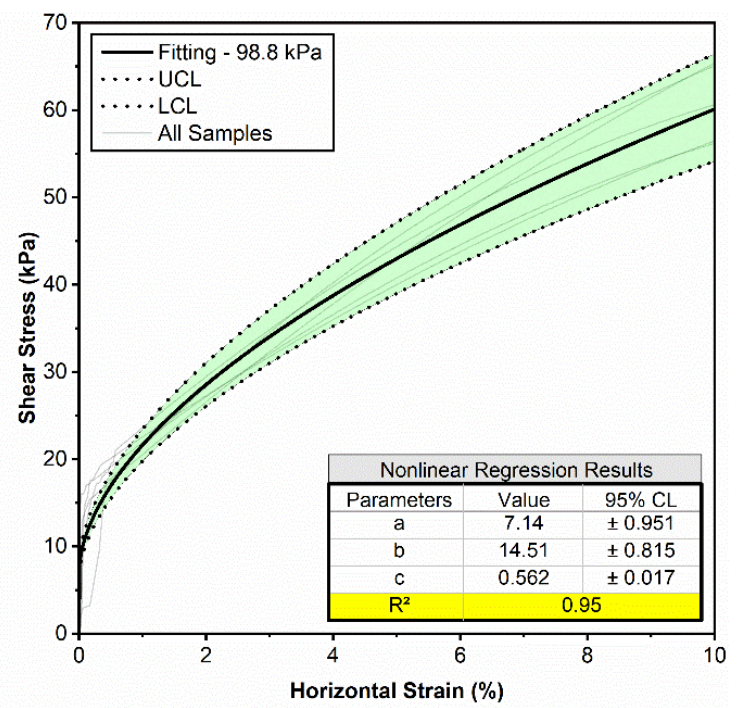

(b)

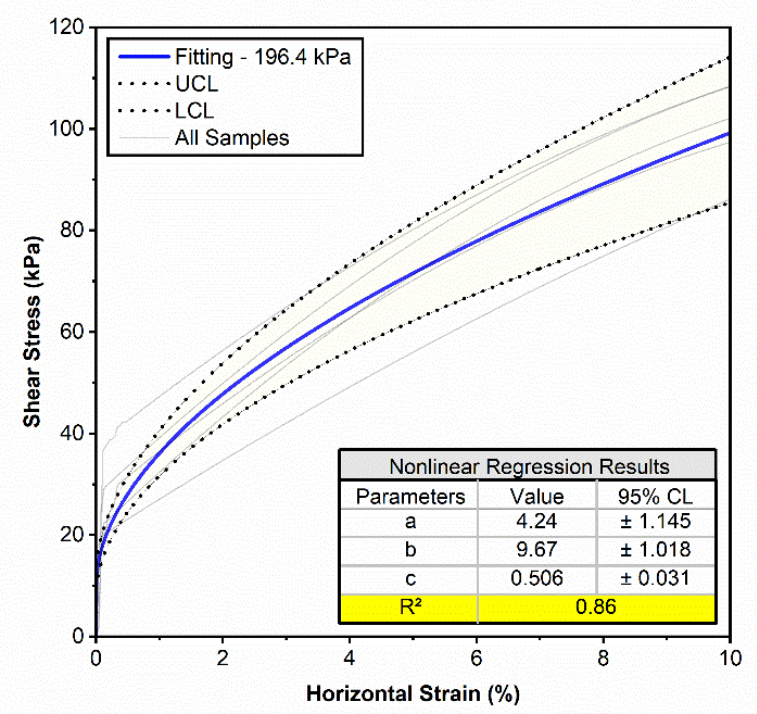

(c)

Figure 9. Non-linear curve fitting for all samples at a normal stress of: (a) $50.1 \mathrm{kPa}$, (b) $98.8 \mathrm{kPa}$ and (c) $198.6 \mathrm{kPa}$.

Table 3. Calibrated parameters for the 2nd degree polynomial equations.

\begin{tabular}{cccc}
\hline Parameters & $p_{1}$ & $p_{2}$ & $p_{3}$ \\
\hline $\mathbf{a}$ & $-1.74 \times 10^{-4}$ & 0.084 & 0.48 \\
UCL-a & $-5.70 \times 10^{-5}$ & 0.063 & 2.4 \\
LCL-a & $-2.90 \times 10^{-4}$ & 0.105 & -1.45 \\
$\mathbf{b}$ & $1.11 \times 10^{-4}$ & 0.08 & 5.38 \\
UCL-b & $2.20 \times 10^{-4}$ & 0.06 & 7.14 \\
LCL-b & $2.94 \times 10^{-6}$ & 0.1 & 3.62 \\
$\mathbf{c}$ & $-9.20 \times 10^{-6}$ & 0.0025 & 0.405 \\
UCL-c & $-7.00 \times 10^{-6}$ & 0.0019 & 0.46 \\
LCL-c & $-1.14 \times 10^{-5}$ & 0.0031 & 0.35 \\
\hline
\end{tabular}




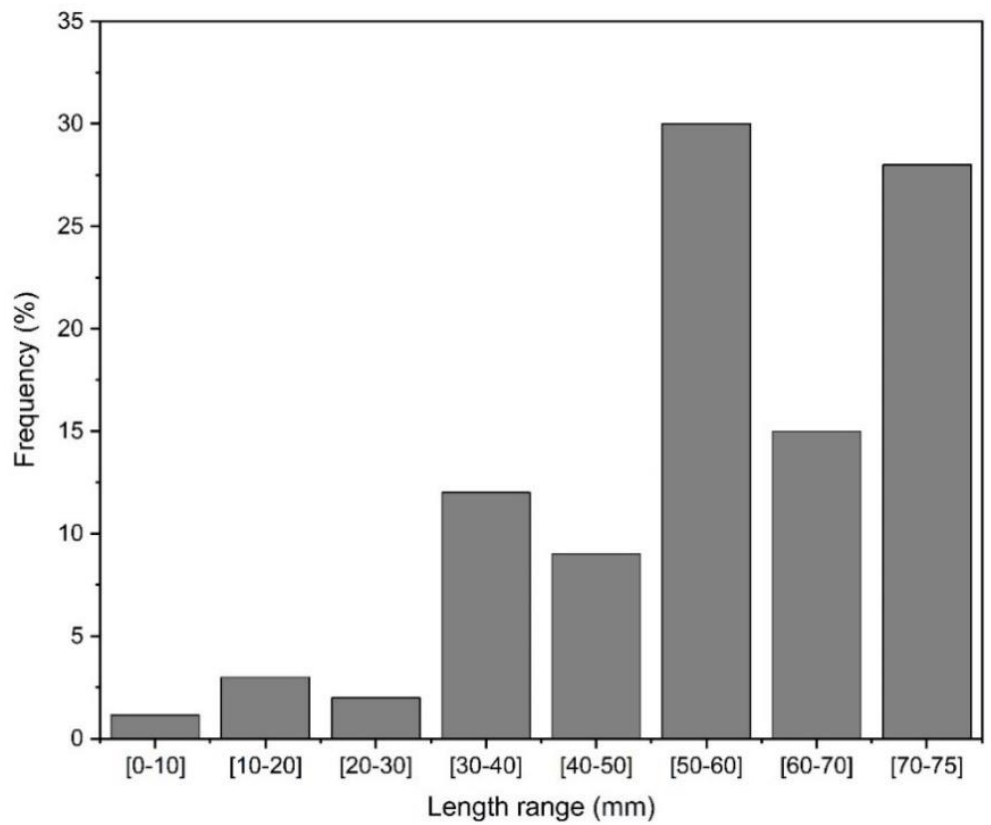

Figure 10. Histogram of TDA aggregate size adapted from Iranikhah and El Naggar [26].

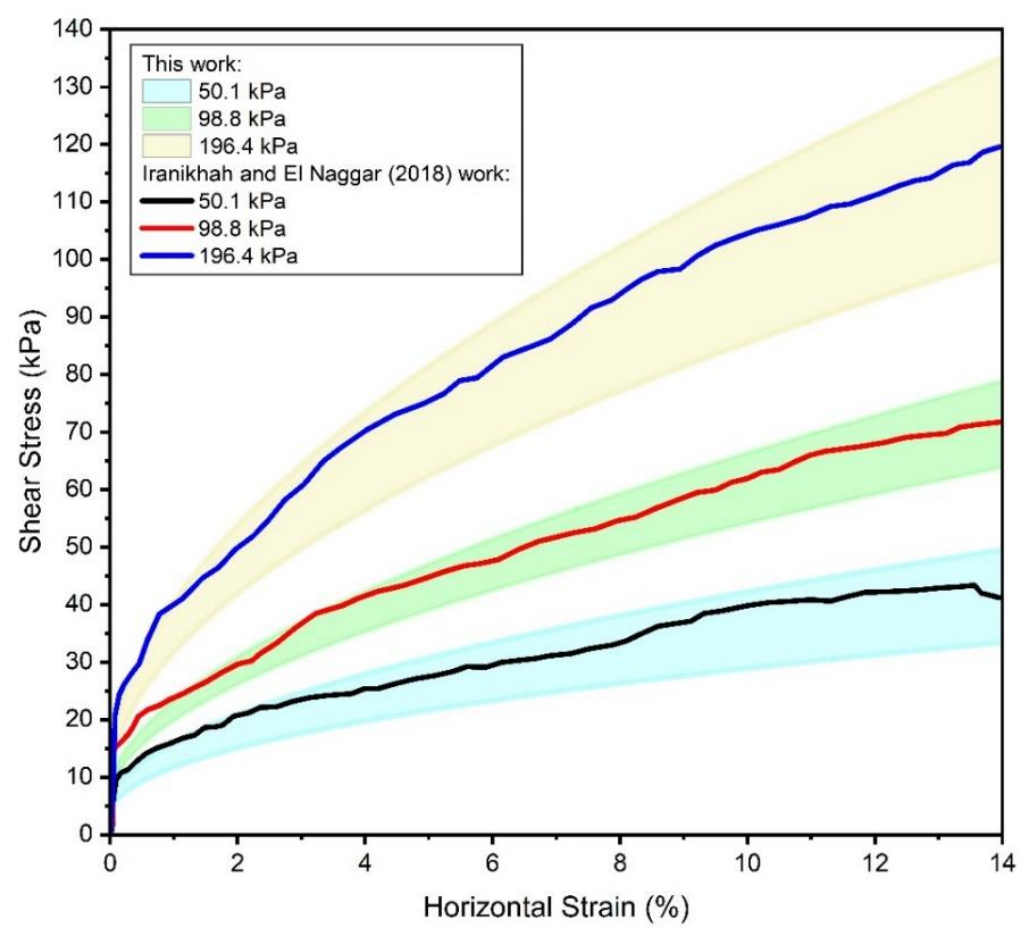

Figure 11. Comparison of developed curves with Iranikhah and El Naggar [26].

In order to assess the applicability of the developed equations under arbitrary TDA maximum aggregate sizes and normal stresses, the stress-strain curves developed by Ghaaowd et al. [27] were compared with the output of this study as shown in Figure 12. Ghaaowd et al. [27] conducted a series of large-scale direct shear tests on TDA samples with a maximum aggregate size of $320 \mathrm{~mm}$ under a normal stress range of 19.5 to $76.7 \mathrm{kPa}$. The reason for selecting the aforementioned study is that the shearing box dimensions, TDA aggregate size, and normal stress range were different from those presented herein. As shown in Figure 12, at each normal stress, the developed equations gave a very good 
estimate which implies the applicability of the developed equations in estimating the stress-strain curves for TDA tested under different testing conditions.
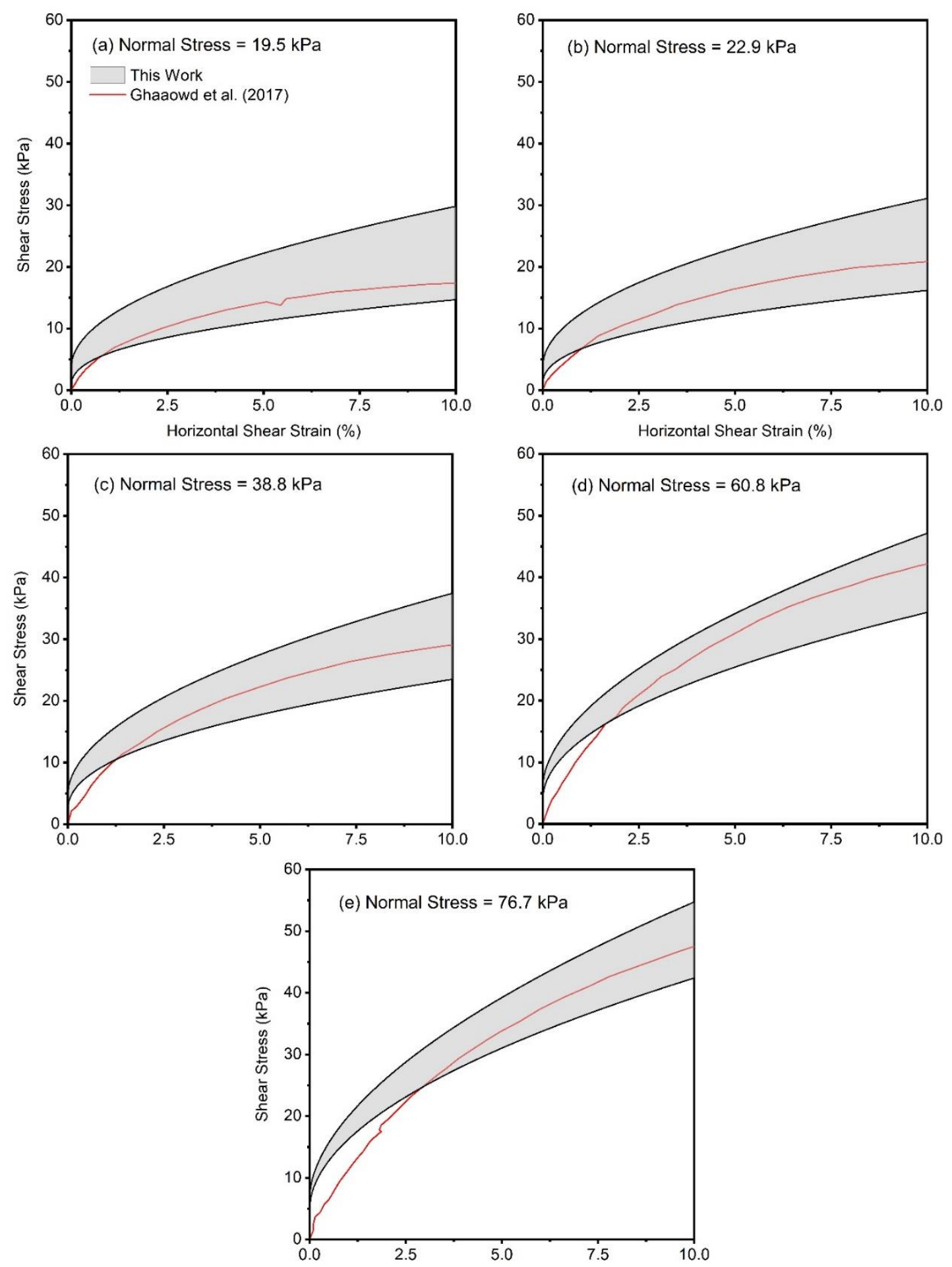

Figure 12. Comparison of developed curves with Ghaaowd et al. [27] at normal stress of: (a) $19.5 \mathrm{kPa}$, (b) $22.9 \mathrm{kPa}$, (c) $38.8 \mathrm{kPa}$, (d) $60.8 \mathrm{kPa}$ and (e) $76.7 \mathrm{kPa}$.

\subsection{Secant Shear Modulus}

The secant shear modulus $\left(G_{50}\right)$ is a mechanical property that is used in this research to define how much shear force is required to cause deformation for TDA particles. The secant shear modulus $\left(G_{50}\right)$ is calculated by dividing $50 \%$ of the shear stress at $10 \%$ strain by 
the corresponding shear strain, as shown in Equation (6) below. The secant shear modulus for the six TDA samples tested is reported below, as shown in Figure 13.

$$
G_{50}=\frac{\tau_{50}}{\varepsilon}
$$

where $\left(\tau_{50}\right)$ is the shear stress at $10 \%$ strain and $(\varepsilon)$ is the corresponding shear strain.

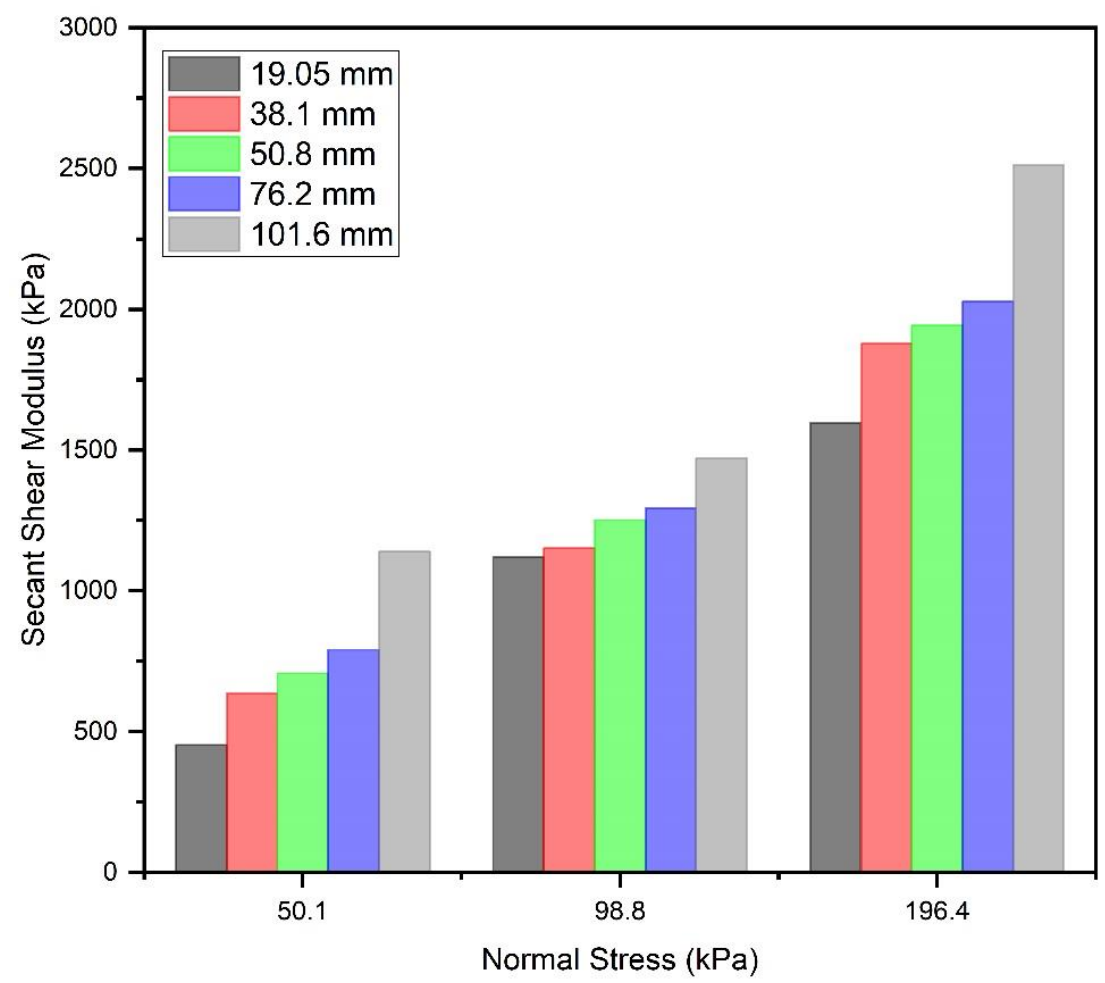

Figure 13. Secant Shear Modulus (kPa).

The secant shear modulus increases by increasing the maximum particle size as the $19.05 \mathrm{~mm}$ sample had a secant shear modulus ranging between 550-1380 $\mathrm{kPa}$. In comparison, the secant shear modulus for the $101.6 \mathrm{~mm}$ sample ranged between 1270 $2800 \mathrm{kPa}$. In addition, the secant shear modulus was found to be stress-dependent as it was found to increase as the applied normal stress increases. Compared to conventional soils, TDA has a relatively low shear modulus, which is attributed to TDA composition, which is mainly made of rubber.

Comparing the secant shear modulus in this study by the one reported by Iranikhah and El Naggar [26] for a TDA sample with a maximum particle size of $75 \mathrm{~mm}$ that was obtained from Halifax C\&D Recycling Ltd. also. Iranikhah and El Naggar [26] reported the secant shear modulus to be within $700-1750 \mathrm{kPa}$, which is in agreement with the range of the secant shear modulus reported in this study and is close to the secant shear modulus of the $76.2 \mathrm{~mm}$ sample reported in this study, which ranges between 870 to $2020 \mathrm{kPa}$. This decrease may be due to the difference in the gradation curves, compacted unit weight and void ratio. However, El Naggar et al. [8] reported the secant shear modulus of three samples; dust, medium and coarse TDA, to be around $400 \mathrm{kPa}$ under $50 \mathrm{kPa}$ normal stress and around $750 \mathrm{kPa}$ under $100 \mathrm{kPa}$, which is expected to be less than the reported shear modulus in this study due to the difference in the particle sizes which was much smaller in El Naggar et al. [8].

\subsection{Strain Behaviour}

The highly elastic material TDA deforms for the following reasons: (a) reorientation of the TDA particles, which is generally irrecoverable when unloaded; (b) compression of the 
TDA particles, unlike conventional soils, and this is generally recoverable when unloaded; (c) bending of TDA particles, unlike conventional soils, and this contributes to the majority of the compression that happens to the TDA when loaded.

Table 4 shows the maximum vertical deformation that occurred for the six samples under the three normal stresses. The maximum difference in the vertical deformation that occurred for the sample increased by increasing the normal stress applied to the sample.

Table 4. Strain behaviour for the TDA samples.

\begin{tabular}{cccc}
\hline \multirow{2}{*}{ Sample $\left(\boldsymbol{D}_{\mathbf{m a x}}\right)$} & \multicolumn{3}{c}{ Maximum Vertical Deformation $\mathbf{( m m )}$} \\
\cline { 2 - 4 } & $\mathbf{5 0 . 1} \mathbf{( k P a )}$ & $\mathbf{9 8 . 8} \mathbf{( k P a )}$ & $\mathbf{1 9 6 . 4} \mathbf{( k P a )}$ \\
\hline $\mathbf{1 0 1 . 6} \mathbf{~ m m}$ & 3.3 & 3.8 & 4.3 \\
$\mathbf{7 6 . 2} \mathbf{~ m m}$ & 2.4 & 3.3 & 3.4 \\
$\mathbf{5 0 . 8} \mathbf{~ m m}$ & 2.6 & 2.7 & 2.8 \\
$\mathbf{3 8 . 1} \mathbf{~} \mathbf{m}$ & 3.2 & 3.6 & 3.9 \\
$\mathbf{1 9 . 0 5} \mathbf{~ m m}$ & 4.1 & 4.8 & 5.6 \\
Maximum & 1.7 & 2.1 & 2.8 \\
Difference $(\mathbf{m m})$ & & & \\
\hline
\end{tabular}

\section{Conclusions}

To study the particle size effect on the TDA's shear strength and stiffness parameters, a series of large-scale direct shear tests were conducted on six different TDA samples using a large scale shear box with dimensions of $305 \mathrm{~mm} \times 305 \mathrm{~mm} \times 230 \mathrm{~mm}$. From the results of the conducted tests, it could be observed that:

(1) The angle of internal friction of TDA increases as the maximum particle size $\left(D_{\max }\right)$ increases.

(2) The cohesion resulted from the interlocking between the TDA particles is not significantly affected by the particle size (the difference was less than $3 \mathrm{kPa}$ ).

(3) All Type A TDA samples exhibited a contractive behavior. Furthermore, smaller TDA aggregates were more compressible that relatively larger TDA aggregates.

(4) The developed equations to estimate the stress-strain curves for large particle sizes presented herein are not limited to the aggregate sizes and depend only on the normal stress and the confidence level.

(5) The suitability of the developed stress-strain equations was verified using several studies' experimental results, and their versatility was proven for other aggregate sizes and normal stresses.

(6) The secant shear modulus of TDA increases as the maximum particle size $\left(D_{\max }\right)$ increases.

Author Contributions: Conceptualization, H.E.N.; Data curation, K.Z. and A.M.; Investigation, H.E.N.; Supervision, H.E.N.; Writing—original draft, H.E.N., K.Z. and A.M.; Writing—review and editing, H.E.N. All authors have read and agreed to the published version of the manuscript.

Funding: This research was funded by The Natural Sciences and Engineering Research Council of Canada (NSERC) and Divert NS.

Data Availability Statement: All data, models, and code generated or used during the study appear in the submitted article.

Acknowledgments: The authors acknowledge the funding provided by the Natural Sciences and Engineering Research Council of Canada (NSERC) and Divert NS for this research project. They are also grateful for Halifax C\&D Recycling Ltd.'s (HCD) support and generosity for supporting this research.

Conflicts of Interest: The authors declare that they have no known competing financial interests or personal relationships that could have appeared to influence the work reported in this paper. 


\section{References}

1. Cecich, V.; Gonzales, L.; Hoisaeter, A.; Williams, J.; Krishna, R. Use of Shredded Tires as Lightweight Backfill Material for Retaining Structure. Waste Manag. Res. 2016, 14, 433-451. [CrossRef]

2. Soltani, A.; Deng, A.; Taheri, A.; O'Kelly, B.C. Engineering Reactive Clay Systems by Ground Rubber Replacement and Polyacrylamide Treatment. Polymers 2019, 11, 1675. [CrossRef] [PubMed]

3. Soltani, A.; Taheri, A.; Deng, A.; O'Kelly, B.C. Improved Geotechnical Behavior of an Expansive Soil Amended with Tire-Derived Aggregates Having Different Gradations. Minerals 2020, 10, 923. [CrossRef]

4. Shahrokhi-Shahraki, R.; Kwon, P.S.; Park, J.; O'Kelly, B.C.; Rezania, S. BTEX and Heavy Metals Removal Using Pulverized Waste Tires in Engineered Fill Materials. Chemosphere 2020, 242, 125281. [CrossRef] [PubMed]

5. ASTM D6270-08(2012). Standard Practice for Use of Scrap Tires in Civil Engineering Applications; ASTM International: West Conshohocken, PA, USA, 2012.

6. Zahran, K.; El Naggar, H. Effect of Sample Size on TDA Shear Strength Parameters in Direct Shear Tests. Transp. Res. Rec. 2020, 2674, 1110-1119. [CrossRef]

7. Sparkes, J.; El Naggar, H.; Valsangkar, A. Compressibility and Shear Strength Properties of Tire Derived Aggregate Mixed with Lightweight Aggregate. J. Pipeline Syst. Eng. Pract ASCE 2019, 10, 04018031. [CrossRef]

8. El Naggar, H.; Soleimani, P.; Fakhroo, A. Strength and Stiffness Properties of Green Lightweight Fill Mixtures. Geotech. Geol. Eng. 2016, 34, 867. [CrossRef]

9. Humphrey, D.N.; Sandford, T.C.; Cribbs, M.M.; Manion, W.P. Shear Strength and Compressibility of Tire Chips for Use as Retaining Wall Backfill. Transp. Res. Rec. 1993, 29-35. Available online: http:/ / onlinepubs.trb.org/Onlinepubs/trr/1993/1422/1422-006.pdf (accessed on 13 November 2020).

10. Mahgoub, A.; El Naggar, H. Using TDA as an Engineered Stress-Reduction Fill over Preexisting Buried Pipes. J. Pipeline Syst. Eng. Pract. 2019, 10, 04018034. [CrossRef]

11. Mahgoub, A.; El Naggar, H. Innovative Application of Tire-Derived Aggregate around Corrugated Steel Plate Culverts. J. Pipeline Syst. Eng. Pract. 2020. [CrossRef]

12. Mahgoub, A.; El Naggar, H. Coupled TDA-Geocell Stress-Bridging System for Buried Corrugated Metal Pipes. J. Geotech. Geoenviron. Eng. 2020, 146. [CrossRef]

13. Mahgoub, A.; El Naggar, H. Using TDA Underneath Shallow Foundations: Field Tests and Numerical Modelling. J. Comput. Geotech. 2020. in production. [CrossRef]

14. Moussa, A.; El Naggar, H. Dynamic Characterization of Tire Derived Aggregates. J. Mater. Civ. Eng. 2020, 33. [CrossRef]

15. Moussa, A.; El Naggar, H. Numerical evaluation of buried wave barriers performance. Int. J. Geosynth. Ground Eng. 2020, 6, 1-13. [CrossRef]

16. Kim, D.; Ha, S. Effects of Particle Size on the Shear Behavior of Coarse Grained Soils Reinforced with Geogrid. Materials 2014, 7, 963-979. [CrossRef]

17. Islam, M.N.; Siddika, A.; Hossain, M.B.; Rahman, A.; Asad, M.A. Effect of particle size on the shear strength behaviour of sands. Aust. Geomech. J. 2011, 46, 85-95.

18. Vangla, P.; Latha, G.M. Influence of Particle Size on the Friction and Interfacial Shear Strength of Sands of Similar Morphology. Int. J. Geosynth. Ground Eng. 2015, 1, 6. [CrossRef]

19. ASTM C136/C136M-14. Standard Test Method for Sieve Analysis of Fine and Coarse Aggregates; ASTM International: West Conshohocken, PA, USA, 2014.

20. ASTM D1557-12e1. Standard Test Methods for Laboratory Compaction Characteristics of Soil Using Modified Effort (56,000 ft-lbf/ft3 (2700 $k N-m / m 3))$; ASTM International: West Conshohocken, PA, USA, 2012.

21. ASTM D3080 / D3080M-11. Standard Test Method for Direct Shear Test of Soils Under Consolidated Drained Conditions; ASTM International: West Conshohocken, PA, USA, 2011.

22. Bernal, A.; Salgado, R.; Swan, R.; Lovell, C. Interaction between tire shreds, rubber-sand, and geosynthetics. Geosynth. Int. 1997, 4, 623-643. [CrossRef]

23. Foose, G.J.; Benson, C.H.; Bosscher, P.J. Sand Reinforced with Shredded Waste Tires. J. Geotech. Eng. 1996. [CrossRef]

24. Xiao, M.; Ledezma, M.; Hartman, C. Shear Resistance of Tire-Derived Aggregate Using Large-Scale Direct Shear Tests. J. Mater. Civ. Eng. 2014, 27. [CrossRef]

25. Freundlich, H. Kapillarchemie, eine Darstellung der Chemie der Kolloide und verwandter Gebiete. Akad. Verlagsgesellschaft 1909.

26. Iranikhah, A.; El Naggar, H. Effect of Tire-Derived Aggregate (TDA) Content on the Shear Strength Parameters of Gravel-TDA Mixtures. In Proceedings of the 71st Canadian Geotechnical Conference (GeoEdmonton 2018), Edmonton, AB, Canada, 23-26 September 2018.

27. Ghaaowd, I.; McCartney, J.S.; Thielmann, S.S.; Sanders, M.J.; Fox, P.J. Shearing behavior of tire-derived aggregate with large particle size. I: Internal and concrete interface direct shear. J. Geotech. Geoenviron. Eng. 2017, 143. [CrossRef] 